Review Article

\title{
Use of Photodynamic Therapy for Treatment of Actinic Keratoses in Organ Transplant Recipients
}

\author{
Christina Wlodek, ${ }^{1}$ Faisal R. Ali, ${ }^{2}$ and John T. Lear ${ }^{2}$ \\ ${ }^{1}$ St Thomas' Hospital, Westminster Bridge Road, London SE1 7EH, UK \\ ${ }^{2}$ The Dermatology Centre, Manchester Academic Health Science Centre, University of Manchester, \\ Salford Royal NHS Foundation Trust, Manchester M6 8HD, UK
}

Correspondence should be addressed to John T. Lear; john.lear@cmft.nhs.uk

Received 27 June 2012; Accepted 5 September 2012

Academic Editor: Mark Berneburg

Copyright (C) 2013 Christina Wlodek et al. This is an open access article distributed under the Creative Commons Attribution License, which permits unrestricted use, distribution, and reproduction in any medium, provided the original work is properly cited.

Solid organ transplant recipients are predisposed to actinic keratoses (AK) and nonmelanoma skin cancers, owing to the lifelong immunosuppression required. Today, increasing numbers of organ transplants are being performed and organ transplant recipients (OTRs) are surviving much longer. Photodynamic therapy (PDT) is proving a highly effective treatment modality for AK amongst this susceptible group of patients. Following an overview of the pathogenesis of AK amongst OTRs, the authors review current safety and efficacy data and how this relates to the role of PDT for the treatment of AK in OTRs.

\section{Introduction}

Actinic keratoses (AK), also known as solar keratoses, are the commonest premalignant dermatological pathology, clinically manifest as hyperkeratotic papules and plaques with an erythematous base and superficial scale with histology demonstrating intraepidermal proliferation of atypical keratinocytes [1]. In addition to cumulative ultraviolet (UV) radiation exposure, particularly UVB, which is the main risk factor for development of $\mathrm{AK}$ and nonmelanoma skin cancer (NMSC) in the general population, susceptibility in organ transplant recipients (OTRs) is significantly increased by long-term exposure to immunosuppressive medications.

\section{Burden of NMSC in Transplant Patients}

Precancerous lesions, including AK and Bowen's disease, are more common in transplant recipients affecting up to $40 \%$ within 5 years of transplantation [2]. Furthermore, organ transplant recipients have shown between a 65 and 250fold increased risk of developing squamous cell carcinoma (SCC) and a 10-fold increased risk of developing basal cell carcinoma (BCC) [3-5].
Skin malignancy is the leading cause of mortality in this group of immunosuppressed patients. The average time for developing SCC is less than 9 years after transplant $[6,7]$. These lesions tend to be more aggressive with an increased propensity for recurrence and metastasis despite treatment $[5,6,8,9]$. Moreover, these patients are prone to developing multiple NMSCs with a 5-year cumulative risk of approximately $70 \%[10,11]$.

Several changes in transplantation trends are responsible for the increasing burden of NMSC observed in these patients. Firstly, the number of transplant procedures continues to increase, partly attributable to the ageing population. With better surgical techniques and more effective immunosuppressive regimes and medical management, recipients are surviving longer [12] and patients are being transplanted at an older age.

\section{Role of Immunosuppressive Medications in AK and NMSC Pathogenesis}

Immunosuppressive drugs can inhibit proinflammatory cytokines, affect the p53 tumour suppressor gene, and 
increase susceptibility to human papilloma virus infection [13-15].

Immunosuppressive medications increase susceptibility to premalignant and malignant skin lesions in a variety of ways. Ciclosporin, a commonly used calcineurin inhibitor (CNI), interferes with repair of damaged DNA and UVBinduced keratinocyte apoptosis [16, 17]. It has also been demonstrated to stimulate synthesis of tumour growth factor beta, which increases tumour invasiveness and metastatic potential $[18,19]$. Other CNIs, including tacrolimus, generate a variety of cytokines promoting angiogenesis and facilitating tumour growth and metastasis [20]. A metabolite of azathioprine, 6-thioguanine, can accumulate in keratinocyte DNA rendering it more sensitive to UVA radiation, with subsequent formation of oxidative DNA photoproducts, increasing the risk of mutagenesis [21].

These findings have led to the development of an alternative class of immunosuppressants-the inhibitors of the mammalian target of rapamycin (mTOR) including everolimus and sirolimus. These drugs exhibit antitumour activity via their inhibition of angiogenesis as well as cell cycle progression and growth. Rival-Tringali et al. demonstrated that switching from a CNI to sirolimus reduced vascularization and thickness of posttransplant human cutaneous SCC in vivo [22]. Following a recent meeting of panEuropean dermatology experts, transplant physicians are being recommended to have recipients switched to these more protective, antineoplastic medications, particularly in patients with documented SCC [13].

Evidence from a variety of organ transplants has revealed that the greater the dose and the longer the duration of immunosuppressive medication OTRs receive, the greater their propensity to develop NMSCs $[23,24]$.

\section{Management of AK and NMSC in OTRs}

As advised by the National Institute of Clinical Excellence in the UK, organ transplant recipients with $\mathrm{AK}$ should be reviewed regularly in a secondary care skin surveillance clinic. The main challenge lies in finely balancing the need to prevent transplant rejection whilst minimising the risk of immunosuppression and its promalignant complications. One of the mainstays of achieving this balance is through active patient education. This includes sun avoidance and regular use of sunscreens, evidenced by a prospective trial that showed daily sunscreen application for 2 years in OTRs resulted in a reduced number of AK and SCC compared to those who did not follow this regimen [25]. Explaining the need for skin vigilance coupled with regular dermatology review is vital. In view of this, it has been suggested each patient has an evaluation of dermatological risk factors (both intrinsic and extrinsic) after transplantation such that a predictive risk for the development of NMSC can be established early after transplant [26].

There are several options available for the active treatment of AK. It is important to distinguish between lesion-directed and field-directed therapies, as in practice most patients will receive both. The most widely used management choice, for small isolated lesions, in immunocompetent individuals is cryotherapy with liquid nitrogen [27]. Cryotherapy is also useful in OTRs to treat solitary AK.

The idea of field change was first described in 1953, and more recently this concept has been demonstrated at molecular level. Patches of genetically altered stem cell clones develop into individual fields that eventually mature into contiguous pastures of precancerous cells [28]. This mandates field therapy rather than targeting individual lesions. Further support for this management concept comes from data showing $82 \%$ of SCCs arising within, in close proximity to, or in a region contiguous with AK. Furthermore, it is acknowledged that the risk of surrounding skin to develop SCC is reduced if $\mathrm{AK}$ lesions are treated [29]. Indeed areas with multiple AK are largely accountable for NMSC-related morbidity and mortality and hence successful treatment should to be field directed [30].

The use of topical therapies, whilst effective, is often limited by the protracted course of treatment required and local side-effects including skin irritation, dryness, erythema, and exfoliation, which are often poorly tolerated by patients. One of the most widely recognised topical agents is 5-fluorouracil (5-FU), a chemotherapeutic agent, which works by inhibiting thymidylate synthetase and consequently disrupting DNA synthesis. In otherwise healthy individuals, when used twice daily for 3 weeks, 5-FU is associated with a reduction of lesional area by 70\% [31]. However, a trial comparing its use with PDT in OTRs found it to be significantly less effective [32].

Imiquimod (5\%) cream is an immune response modifier that acts via stimulation of a Toll-like receptor culminating in malignant cell apoptosis and a local Th1-based immune response. Randomised controlled trials have demonstrated its efficacy both clinically and histologically over a 16-week treatment course $[33,34]$. Complete clinical clearance was achieved in $47 \%$ of patients and partial in $64 \%$. Furthermore this efficacy has been echoed in OTRs even though it lacks official approval for this patient group [35]. Nevertheless it should be used with caution in this population given its potential to increase systemic interferon levels and hence theoretically the risk of graft rejection [13]. It is more expensive than 5-FU with a similar side effect profile, including severe erythema as well as scabbing and crusting (30\%) with some ulceration (10\%) [36].

Diclofenac gel, a topical nonsteroidal anti-inflammatory agent, is another treatment option for AK. Although not specifically licensed for OTRs, it does have a safe evidence base, with a complete clearance rate of $41 \%$ and a $53 \%$ reduction in the number of individual lesions after four weeks of treatment [37].

\section{Photodynamic Therapy}

PDT combines the use of a photosensitising drug with targeted phototherapy to act on rapidly dividing atypical keratinocytes with treatment rates in immunocompetent individuals approaching $90 \%[27,38,39]$. PDT is particularly useful when lesions are numerous and located in areas of 
poor wound healing $[36,40]$. In a randomized intraindividual study, Morton et al. compared PDT with double freezethaw cryotherapy in otherwise healthy individuals, repeating treatments at three months if required. After 24 weeks both groups had similarly high response rates but cosmetic outcome and satisfaction were significantly higher in the PDT group [41]. PDT with either 5-aminolevulinic acid (ALA) or methylaminolevulinic acid (MAL) is a well-recognised treatment modality for $\mathrm{AK}$ [42] as well as superficial and nodular BCC in OTRs [43].

The success of PDT relies upon adequate penetration of the relevant wavelengths of light, hence sufficient production of protoporphyrin IX, together with optimal cellular uptake of photosensitizer. The former can be negatively affected if lesions are particularly hyperkeratotic, as is often the case with AKs in OTRs $[44,45]$. In the case of stubborn NMSCs, it has proved useful to aggressively debulk tumours prior to PDT with a variety of methods including curettage [4648], keratolytics [49], fractional laser techniques [50], and laser ablation [51]. Hence, clinical assessment of $\mathrm{AK}$ and appropriate preconditioning of lesions are paramount for optimal treatment with PDT.

Dragieva et al. were the first to compare the use of PDT for AK and Bowen's disease in a group of immunocompetent patients compared to those on immunosuppressants. In the first instance, 4 weeks after intervention, the complete clearance rate was comparable between the two groups (94\% and $86 \%)$. However, in the longer term (48 weeks after treatment) the results were much poorer with complete clearance being achieved in $48 \%$ of the immunocompromised population compared to $72 \%$ in the control group [32]. Echoing the findings in immunocompetent patients, the final therapeutic PDT outcome is better on the face and scalp compared to the hands [52, 53]. Analysis of the trials thus far suggests at least two PDT sessions should be performed in field cancerisation areas at baseline (1-2 weeks apart), followed by further sessions several times per year. This regimen appears to provide adequate clearance of $\mathrm{AK}$ for up to 3 months in OTRs $[13,54]$.

In addition to the markedly hyperkeratotic nature of many lesions seen in OTRs, another contributory factor to the inferior efficacy of PDT upon a given lesion in the OTR population is the impaired ability of immunosuppressed OTRs to mount an adequate immune response. The mode of action of PDT relies in part on its induction of a local immune reaction that in turn eliminates mutagenic cells. Unsurprisingly therefore, this response will be hampered in immunosuppressed individuals [55]. This was confirmed in the case of BCC in OTRs, whereby the density of the perilesional inflammatory infiltrate was significantly reduced compared to immunocompetent cases [56].

One study comparing MAL-PDT to 5-FU demonstrated a complete clearance rate at 4 weeks of $89 \%$ with MALPDT compared to just $11 \%$ with 5 -FU. Despite pain being a considerable side effect, PDT offered the best cosmetic outcome and was the preferred treatment option by patients [42].

In addition to short-term aesthetic benefit, evidence supports the role of PDT in reducing carcinogenesis. Bagazgoitia et al. demonstrated its action at molecular level through decreased expression of p53, which is a marker of early skin cancer [54].

Cyclical ALA-PDT has also been shown to reduce the incidence of new SCC in OTRs, which when used for two years, has been shown to lead to a mean reduction in new SCC and Bowen's disease of 95\% compared to baseline [57]. Further support for the use of PDT in prevention of NMSC came from a Danish group who showed that one session of MAL PDT in renal transplant patients significantly increased the mean time to occurrence of a new NMSC lesion to 9.6 months (versus 6.8 months in controls) [58], findings that have recently been validated in a separate population, confirming that regular field PDT has the potential to prevent AK in the OTR population [59].

Although the number of reported studies so far is small, PDT in OTRs appears to be more effective for BCC than AK with remission rates of $75 \%$ after 12 weeks, compared to $48 \%$ in $\mathrm{AK}$ [60], and a low recurrence rate of under $6 \%$ after 22 months of followup $[43,61]$.

\section{Adverse Events of PDT}

An analysis of all the reported adverse events, from studies involving over 200 OTRs who underwent PDT, revealed no damage to the graft [13]. The risk of further immunosuppression from PDT, particularly in OTRs, is however undefined due to limited investigations to date. However, given the knowledge that PDT not only recruits proinflammatory factors but also local immunosuppressive interleukins and tumour necrosis factor alpha $[62,63]$, there is a real possibility that further local immunosuppression may impair the response to infection. In keeping with this, recently it has been suggested that there is a suppressed local Mantoux response in healthy volunteers who have received MAL- and ALA-PDT [64]; however, these results have not yet been independently replicated. Furthermore, there is a documented case of confined herpes simplex reactivation in a patient who received $\mathrm{PDT}$ to the forehand for $\mathrm{AK}$ [65]. As a means to limit this phenomenon, it has been proposed that by reducing the rate of irradiation, whilst maintaining the same light dose, immunosuppression can be prevented [66]. To date, there is no compelling evidence that PDT causes long-term deleterious immunosuppression in patients with $\mathrm{AK}$ or other NMSC.

Owing to pain being the most common and limiting side effect of PDT, a number of studies have looked into analgesic options. Although there is no direct evidence, OTRs seem to be more affected than other individuals, particularly with lesions on the head and scalp requiring field therapy. This is likely to reflect size, number, and induration of their lesions compared to immunocompetent patients [67]. It seems that nerve blocks provide relatively uncomplicated yet effective pain relief for patients requiring extensive treatment, particularly when involving sensitive areas on the face and scalp, with significantly reduced pain visual analogue scores reported within a field to which a nerve block was applied compared to the untreated side $[68,69]$. Other options 
reported include transcutaneous electrical nerve stimulation (TENS) [70] and simple cold air fans [71] and cold water sprays [72]. Curiously, topical lidocaine and similar products appear to be no better than placebo [73].

\section{Alternative Emerging Treatment Modalities}

Ingenol mebutate, derived from the plant Euphorbia peplus, was licensed for use in AK by the U.S. Food and Drug Administration in January 2012. This novel treatment has a dual mode of action via both cellular necrosis and neutrophilmediated, antibody-dependent cellular cytotoxicity [74, 75]. Phase III trial data suggested that just two days of fielddirected application of $0.05 \%$ ingenol mebutate on the trunk and extremities, or three days of field-directed application of $0.015 \%$ ingenol mebutate, are significantly more efficacious than vehicle control with respect to complete and partial clearance of lesions [76]. The new product also appears to be well-tolerated and is likely to exhibit high adherence rates given that only a short duration of application is required [77].

Another plant extract showing promise in the treatment of $\mathrm{AK}$ is betulinic acid. Its chemical structure is that of pentacyclic triterpenoid, which is extracted from birch bark. In addition to its antimicrobial and antiviral properties, it has more recently been discovered to induce apoptosis and hence shown promise as an antineoplastic agent [78]. A randomised comparative Phase IIa study with 45 patients, each with less than 10 facial and scalp AKs, showed a complete clearance rate of $64 \%$ after twice daily application of betulin-based oleogel for a total of 3 months, compared to $79 \%$ with cryotherapy and $71 \%$ with a combination of the two treatments [79].

An immune response modifier, resiquimod, has similar molecular effects to imiquimod and is another emergent topical treatment of AK. It also acts as an agonist at Tolllike receptors 7 and 8 , however, is more potent than its counterpart with the induction of additional chemokines and interleukins resulting in the activation of myeloid and plasmacytoid dendritic cells [80]. A phase II dosing study of resiquimod gel in 132 patients used once daily application, three times per week, for 4 weeks to a contiguous $25 \mathrm{~cm}^{2}$ area baring four to eight lesions. The escalating gel concentrations showed a range of complete clearance rates from $40 \%$ to $70 \%$. Unsurprisingly, tolerance was greatest with $0.01 \%$ and $0.03 \%$ concentrations $[81,82]$.

\section{Conclusion}

NMSCs, including AKs, are a common problem in OTRs who are maintained on lifelong immunosuppressive agents. Management begins with prevention through patient education of sun protective measures and reduction of dose of immunosuppressants with the possible use of less harmful immunosuppressive drugs such as mTOR inhibitors.

PDT is a safe, well-tolerated treatment option for NMSCs and remains an effective treatment modality for OTRs. However, it should be recalled that PDT appears to be less effective in the longer term for individual lesions in immunosuppressed patients compared to the healthy population, and therefore OTRs need earlier and numerous treatment at regular intervals to obtain the best response and possibly prevent development of new AK and NMSC.

\section{Acknowledgments}

J. T. Lear has accepted honoraria for speaking at meetings by Leo, Galderma, Almirall, Astellas, and GSK.

\section{References}

[1] V. Madan, J. T. Lear, and R. M. Szeimies, "Non-melanoma skin cancer," The Lancet, vol. 375, no. 9715, pp. 673-685, 2010.

[2] S. Euvrard, J. Kanitakis, C. Pouteil-Noble et al., "Comparative epidemiologic study of premalignant and malignant epithelial cutaneous lesions developing after kidney and heart transplantation," Journal of the American Academy of Dermatology, vol. 33, no. 2, part 1, pp. 222-229, 1995.

[3] D. Berg and C. C. Otley, "Skin cancer in organ transplant recipients: epidemiology, pathogenesis, and management," Journal of the American Academy of Dermatology, vol. 47, no. 1, pp. 1-17, 2002.

[4] M. M. Hartevelt, J. N. Bouwes Bavinck, A. M. Kootte, B. J. Vermeer, and J. P. Vandenbroucke, "Incidence of skin cancer after renal transplantation in the Netherlands," Transplantation, vol. 49, no. 3, pp. 506-509, 1990.

[5] P. Jensen, S. Hansen, B. Moller et al., "Skin cancer in kidney and heart transplant recipients and different long-term immunosuppressive therapy regimens," Journal of the American Academy of Dermatology, vol. 40, no. 2, pp. 177-186, 1999.

[6] E. Stockfleth, C. Ulrich, T. Meyer, and E. Christophers, "Epithelial malignancies in organ transplant patients: clinical presentation and new methods of treatment," Recent Results in Cancer Research, vol. 160, pp. 251-258, 2002.

[7] M. C. Webb, F. Compton, P. A. Andrews, and G. G. Koffman, "Skin tumours posttransplantation: a retrospective analysis of 28 years' experience at a single centre," Transplantation Proceedings, vol. 29, no. 1-2, pp. 828-830, 1997.

[8] R. Adamson, E. Obispo, S. Dychter et al., "High incidence and clinical course of aggressive skin cancer in heart transplant patients: a single-center study," Transplantation Proceedings, vol. 30, no. 4, pp. 1124-1126, 1998.

[9] J. C. Martinez, C. C. Otley, T. Stasko et al., "Defining the clinical course of metastatic skin cancer in organ transplant recipients: a multicenter collaborative study," Archives of Dermatology, vol. 139, no. 3, pp. 301-306, 2003.

[10] H. C. Wisgerhof, J. R. J. Edelbroek, J. W. De Fijter et al., "Subsequent squamous-and basal-cell carcinomas in kidneytransplant recipients after the first skin cancer: cumulative incidence and risk factors," Transplantation, vol. 89, no. 10, pp. 1231-1238, 2010.

[11] S. Euvrard, J. Kanitakis, E. Decullier et al., "Subsequent skin cancers in kidney and heart transplant recipients after the first squamous cell carcinoma," Transplantation, vol. 81, no. 8, pp. 1093-1100, 2006.

[12] S. Hariharan, C. P. Johnson, B. A. Bresnahan, S. E. Taranto, and M. J. McIntosh, "Erratum: Improved graft survival after renal transplantation in the United States, 1988 to 1996," New England Journal of Medicine, vol. 342, no. 24, pp. 1837-1938, 1837. 
[13] N. Basset-Seguin, K. Baumann Conzett, M. J. P. Gerritsen, H. Gonzalez, M. Haedersdal, G. F. L. Hofbauer et al., "Photodynamic therapy for actinic keratosis in organ transplant patients," Journal of the European Academy of Dermatology and Venereology, 2011. In press.

[14] M. G. Lebwohl, T. Rosen, and E. Stockfleth, "The role of human papillomavirus in common skin conditions: current viewpoints and therapeutic options," Cutis, vol. 86, no. 5, supplement 1-11, pp. 1-12, 2010.

[15] C. A. Harwood and C. M. Proby, "Human papillomaviruses and non-melanoma skin cancer," Current Opinion in Infectious Diseases, vol. 15, no. 2, pp. 101-114, 2002.

[16] D. B. Yarosh, M. T. Canning, D. Teicher, and D. A. Brown, "After sun reversal of DNA damage: enhancing skin repair," Mutation Research, vol. 571, no. 1-2, pp. 57-64, 2005.

[17] D. B. Yarosh, A. V. Pena, S. L. Nay, M. T. Canning, and D. A. Brown, "Calcineurin inhibitors decrease DNA repair and apoptosis in human keratinocytes following ultraviolet B irradiation," Journal of Investigative Dermatology, vol. 125, no. 5, pp. 1020-1025, 2005.

[18] N. André, B. Roquelaure, and J. Conrath, "Molecular effects of cyclosporine and oncogenesis: a new model," Medical Hypotheses, vol. 63, no. 4, pp. 647-652, 2004.

[19] M. Hojo, T. Morimoto, M. Maluccio et al., "Cyclosporine induces cancer progression by a cell-autonomous mechanism," Nature, vol. 397, no. 6719, pp. 530-534, 1999.

[20] M. Guba, C. Graeb, K. W. Jauch, and E. K. Geissler, "Pro- and anti-cancer effects of immunosuppressive agents used in organ transplantation," Transplantation, vol. 77, no. 12, pp. 1777-1782, 2004.

[21] P. O’Donovan, C. M. Perrett, X. Zhang et al., "Medicine: azathioprine and UVA light generate mutagenic oxidative DNA damage," Science, vol. 309, no. 5742, pp. 1871-1874, 2005.

[22] A. L. Rival-Tringali, S. Euvrard, E. Decullier, A. Claudy, M. Faure, and J. Kanitakis, "Conversion from calcineurin inhibitors to sirolimus reduces vascularization and thickness of post-transplant cutaneous squamous cell carcinomas," Anticancer Research, vol. 29, no. 6, pp. 1927-1932, 2009.

[23] E. E. Frezza, J. J. Fung, and D. H. Van Thiel, "Non-lymphoid cancer after liver transplantation," Hepato-Gastroenterology, vol. 44, no. 16, pp. 1172-1181, 1997.

[24] A. L. P. Caforio, A. B. Fortina, S. Piaserico et al., "Skin cancer in heart transplant recipients: risk factor analysis and relevance of immunosuppressive therapy," Circulation, vol. 102, no. 19, supplement 3, pp. III222-III227, 2000.

[25] C. Ulrich, J. S. Jürgensen, A. Degen et al., "Prevention of nonmelanoma skin cancer in organ transplant patients by regular use of a sunscreen: a 24 months, prospective, case-control study," British Journal of Dermatology, vol. 161, supplement 3, pp. 78-84, 2009.

[26] C. Ulrich, J. Kanitakis, E. Stockfleth, and S. Euvrard, "Skin cancer in organ transplant recipients-where do we stand today?" American Journal of Transplantation, vol. 8, no. 11, pp. 2192-2198, 2008.

[27] R. M. Szeimies, S. Karrer, S. Radakovic-Fijan et al., "Photodynamic therapy using topical methyl 5-aminolevulinate compared with cryotherapy for actinic keratosis: a prospective, randomized study," Journal of the American Academy of Dermatology, vol. 47, no. 2, pp. 258-262, 2002.
[28] B. J. M. Braakhuis, M. P. Tabor, J. A. Kummer, C. R. Leemans, and R. H. Brakenhoff, "A genetic explanation of slaughter's concept of field cancerization: evidence and clinical implications," Cancer Research, vol. 63, no. 8, pp. 1727-1730, 2003.

[29] M. A. Mittelbronn, D. L. Mullins, F. A. Ramos-Caro, and F. P. Flowers, "Frequency of pre-existing actinic keratosis in cutaneous squamous cell carcinoma," International Journal of Dermatology, vol. 37, no. 9, pp. 677-681, 1998.

[30] C. Ulrich, M. Hackethal, M. Ulrich et al., "Treatment of multiple actinic keratoses with topical diclofenac 3\% gel in organ transplant recipients: a series of six cases," British Journal of Dermatology, vol. 156, supplement s3, pp. 40-42, 2007.

[31] H. A. Kurwa, S. A. Yong-Gee, P. T. Seed, A. C. Markey, and R. J. Barlow, "A randomized paired comparison of photodynamic therapy and topical 5- fluorouracil in the treatment of actinic keratoses," Journal of the American Academy of Dermatology, vol. 41, no. 3, part 1, pp. 414-418, 1999.

[32] G. Dragieva, J. Hafner, R. Dummer et al., “Topical photodynamic therapy in the treatment of actinic keratoses and Bowen's disease in transplant recipients," Transplantation, vol. 77, no. 1, pp. 115-121, 2004.

[33] R. M. Szeimies, M. J. P. Gerritsen, G. Gupta et al., "Imiquimod $5 \%$ cream for the treatment of actinic keratosis: results from a phase III, randomized, double-blind, vehicle-controlled, clinical trial with histology," Journal of the American Academy of Dermatology, vol. 51, no. 4, pp. 547-555, 2004.

[34] N. Korman, R. Moy, M. Ling et al., "Dosing with 5\% imiquimod cream 3 times per week for the treatment of actinic keratosis: results of two phase 3, randomized, double-blind, parallelgroup, vehicle-controlled trials," Archives of Dermatology, vol. 141, no. 4, pp. 467-473, 2005.

[35] C. Ulrich, J. Bichel, S. Euvrard et al., "Topical immunomodulation under systemic immunosuppression: results of a multicentre, randomized, placebo-controlled safety and efficacy study of imiquimod $5 \%$ cream for the treatment of actinic keratoses in kidney, heart, and liver transplant patients," British Journal of Dermatology, vol. 157, supplement s2, pp. 25-31, 2007.

[36] D. De Berker, J. M. McGregor, and B. R. Hughes, "Guidelines for the management of actinic keratoses," British Journal of Dermatology, vol. 156, no. 2, pp. 222-230, 2007.

[37] C. Ulrich, A. Johannsen, J. Röwert-Huber, M. Ulrich, W. Sterry, and E. Stockfleth, "Results of a randomized, placebo-controlled safety and efficacy study of topical diclofenac 3\% gel in organ transplant patients with multiple actinic keratoses," European Journal of Dermatology, vol. 20, no. 4, pp. 482-488, 2010.

[38] D. M. Pariser, N. J. Lowe, D. M. Stewart et al., "Photodynamic therapy with topical methyl aminolevulinate for actinic keratosis: results of a prospective randomized multicenter trial," Journal of the American Academy of Dermatology, vol. 48, no. 2, pp. 227-232, 2003.

[39] M. Freeman, C. Vinciullo, D. Francis et al., "A comparison of photodynamic therapy using topical methyl aminolevulinate $\left(\right.$ Metvix $\left.^{\otimes}\right)$ with single cycle cryotherapy in patients with actinic keratosis: a prospective, randomized study," Journal of Dermatological Treatment, vol. 14, no. 2, pp. 99-106, 2003.

[40] L. R. Braathen, R. M. Szeimies, N. Basset-Seguin et al., "Guidelines on the use of photodynamic therapy for nonmelanoma skin cancer: an international consensus," Journal of the American Academy of Dermatology, vol. 56, no. 1, pp. 125-143, 2007. 
[41] C. Morton, S. Campbell, G. Gupta et al., "Intraindividual, right-left comparison of topical methyl aminolaevulinatephotodynamic therapy and cryotherapy in subjects with actinic keratoses: a multicentre, randomized controlled study," British Journal of Dermatology, vol. 155, no. 5, pp. 1029-1036, 2006.

[42] C. M. Perrett, J. M. McGregor, J. Warwick et al., "Treatment of post-transplant premalignant skin disease: a randomized intrapatient comparative study of 5-fluorouracil cream and topical photodynamic therapy," British Journal of Dermatology, vol. 156, no. 2, pp. 320-328, 2007.

[43] G. E. Guleng and P. Helsing, "Photodynamic therapy for basal cell carcinomas in organ-transplant recipients," Clinical and Experimental Dermatology, vol. 37, no. 4, pp. 367-369, 2012.

[44] T. Smits, M. M. Kleinpenning, W. A. M. Blokx, P. C. M. van de Kerkhof, P. E. J. van Erp, and M. J. P. Gerritsen, "Fluorescence diagnosis in keratinocytic intraepidermal neoplasias," Journal of the American Academy of Dermatology, vol. 57, no. 5, pp. 824-831, 2007.

[45] M. J. P. Gerritsen, T. Smits, M. M. Kleinpenning, P. C. M. Van De Kerkhof, and P. E. J. Van Erp, "Pretreatment to enhance protoporphyrin IX accumulation in photodynamic therapy," Dermatology, vol. 218, no. 3, pp. 193-202, 2009.

[46] L. Berroeta, C. Clark, R. S. Dawe, S. H. Ibbotson, and C. J. Fleming, "A randomized study of minimal curettage followed by topical photodynamic therapy compared with surgical excision for low-risk nodular basal cell carcinoma," British Journal of Dermatology, vol. 157, no. 2, pp. 401-403, 2007.

[47] C. S. Souza, A. B. S. Neves, L. A. B. Felício, J. Ferreira, C. Kurachi, and V. S. Bagnato, "Optimized photodynamic therapy with systemic photosensitizer following debulking technique for nonmelanoma skin cancers," Dermatologic Surgery, vol. 33, no. 2, pp. 194-198, 2007.

[48] A. M. Soler, T. Warloe, A. Berner, and K. E. Giercksky, "A follow-up study of recurrence and cosmesis in completely responding superficial and nodular basal cell carcinomas treated with methyl 5-aminolaevulinate-based photodynamic therapy alone and with prior curettage," British Journal of Dermatology, vol. 145, no. 3, pp. 467-471, 2001.

[49] M. M. Kleinpenning, J. H. Kanis, T. Smits, P. E. J. Van Erp, P. Van De Kerkhof, and R. M. J. P. Gerritsen, "The effects of keratolytic pretreatment prior to fluorescence diagnosis and photodynamic therapy with aminolevulinic acid-induced porphyrins in psoriasis," Journal of Dermatological Treatment, vol. 21, no. 4, pp. 245-251, 2010.

[50] M. Hædersdal, F. H. Sakamoto, W. A. Farinelli, A. G. Doukas, J. Tam, and R. R. Anderson, "Fractional CO2 laser-assisted drug delivery," Lasers in Surgery and Medicine, vol. 42, no. 2, pp. 113-122, 2010.

[51] J. Y. Fang, W. R. Lee, S. C. Shen, Y. P. Fang, and C. H. $\mathrm{Hu}$, "Enhancement of topical 5-aminolaevulinic acid delivery by erbium:YAG laser and microdermabrasion: a comparison with iontophoresis and electroporation," British Journal of Dermatology, vol. 151, no. 1, pp. 132-140, 2004.

[52] S. Piaserico, A. Belloni Fortina, P. Rigotti et al., "Topical photodynamic therapy of actinic keratosis in renal transplant recipients," Transplantation Proceedings, vol. 39, no. 6, pp. 1847-1850, 2007.

[53] G. Dragieva, B. M. Prinz, J. Hafner et al., "A randomized controlled clinical trial of topical photodynamic therapy with methyl aminolaevulinate in the treatment of actinic keratoses in transplant recipients," British Journal of Dermatology, vol. 151, no. 1, pp. 196-200, 2004.

[54] L. Bagazgoitia, J. Cuevas Santos, A. Juarranz, and P. Jaén, "Photodynamic therapy reduces the histological features of actinic damage and the expression of early oncogenic markers," British Journal of Dermatology, vol. 165, no. 1, pp. 144-151, 2011.

[55] A. P. Castano, P. Mroz, and M. R. Hamblin, "Photodynamic therapy and anti-tumour immunity," Nature Reviews Cancer, vol. 6, no. 7, pp. 535-545, 2006.

[56] J. Kanitakis, L. Alhaj-Ibrahim, S. Euvrard, and A. Claudy, "Basal cell carcinomas developing in solid organ transplant recipients: clinicopathologic study of 176 cases," Archives of Dermatology, vol. 139, no. 9, pp. 1133-1137, 2003.

[57] A. Willey, S. Mehta, and P. K. Lee, "Reduction in the incidence of squamous cell carcinoma in solid organ transplant recipients treated with cyclic photodynamic therapy," Dermatologic Surgery, vol. 36, no. 5, pp. 652-658, 2010.

[58] H. C. Wulf, S. Pavel, I. Stender, and C. Ahb BakkerWensveen, "Topical photodynamic therapy for prevention of new skin lesions in renal transplant recipients," Acta DermatoVenereologica, vol. 86, no. 1, pp. 25-28, 2006.

[59] A. M. Wennberg, B. Stenquist, E. Stockfleth et al., "Photodynamic therapy with methyl aminolevulinate for prevention of new skin lesions in transplant recipients: a randomized study," Transplantation, vol. 86, no. 3, pp. 423-429, 2008.

[60] P. Schleier, P. Hyckel, A. Berndt et al., "Photodynamic therapy of virus-associated epithelial tumours of the face in organ transplant recipients," Journal of Cancer Research and Clinical Oncology, vol. 130, no. 5, pp. 279-284, 2004.

[61] C. M. Perrett, S. K. Tan, R. Cerio et al., "Treatment of basal cell carcinoma with topical methylaminolaevulinate photodynamic therapy in an organ-transplant recipient," Clinical and Experimental Dermatology, vol. 31, no. 1, pp. 146-147, 2006.

[62] S. O. Gollnick, S. S. Evans, H. Baumann et al., "Role of cytokines in photodynamic therapy-induced local and systemic inflammation," British Journal of Cancer, vol. 88, no. 11, pp. 1772-1779, 2003.

[63] A. D. Garg, D. Nowis, J. Golab, and P. Agostinis, "Photodynamic therapy: illuminating the road from cell death towards anti-tumour immunity," Apoptosis, vol. 15, no. 9, pp. 1050-1071, 2010.

[64] Y. J. Matthews and D. L. Damian, "Topical photodynamic therapy is immunosuppressive in humans," British Journal of Dermatology, vol. 162, no. 3, pp. 637-641, 2010.

[65] S. Nobbe, R. M. Trüeb, L. E. French, and G. F. L. Hofbauer, "Herpes simplex virus reactivation as a complication of photodynamic therapy," Photodermatology Photoimmunology and Photomedicine, vol. 27, no. 1, pp. 51-52, 2011.

[66] G. A. Frost, G. M. Halliday, and D. L. Damian, "Photodynamic therapy-induced immunosuppression in humans is prevented by reducing the rate of light delivery," Journal of Investigative Dermatology, vol. 131, no. 4, pp. 962-968, 2011.

[67] A. H. M. M. Arits, M. M. Van De Weert, P. J. Nelemans, and N. W. J. Kelleners-Smeets, "Pain during topical photodynamic therapy: uncomfortable and unpredictable," Journal of the European Academy of Dermatology and Venereology, vol. 24, no. 12, pp. 1452-1457, 2010.

[68] J. Paoli, C. Halldin, M. B. Ericson, and A. M. Wennberg, "Nerve blocks provide effective pain relief during topical photodynamic therapy for extensive facial actinic keratoses," Clinical and Experimental Dermatology, vol. 33, no. 5, pp. 559-564, 2008. 
[69] C. B. Halldin, J. Paoli, C. Sandberg, H. Gonzalez, and A. M. Wennberg, "Nerve blocks enable adequate pain relief during topical photodynamic therapy of field cancerization on the forehead and scalp," British Journal of Dermatology, vol. 160, no. 4, pp. 795-800, 2009.

[70] C. B. Halldin, J. Paoli, C. Sandberg, M. B. Ericson, and A. M. Wennberg, "Transcutaneous electrical nerve stimulation for pain relief during photodynamic therapy of actinic keratoses," Acta Dermato-Venereologica, vol. 88, no. 3, pp. 311-313, 2008.

[71] J. Pagliaro, T. Elliott, M. Bulsara, C. King, and C. Vinciullo, "Cold air analgesia in photodynamic therapy of basal cell carcinomas and Bowen's disease: an effective addition to treatment: a pilot study," Dermatologic Surgery, vol. 30, no. 1, pp. 63-66, 2004.

[72] S. R. Wiegell, M. Hædersdal, and H. C. Wulf, "Cold water and pauses in illumination reduces pain during photodynamic therapy: a randomized clinical study," Acta Dermato-Venereologica, vol. 89, no. 2, pp. 145-149, 2009.

[73] S. M. Langan and P. Collins, "Randomized, double-blind, placebo-controlled prospective study of the efficacy of topical anaesthesia with a eutetic mixture of lignocaine $2.5 \%$ and prilocaine $2.5 \%$ for topical 5 -aminolaevulinic acid-photodynamic therapy for extensive scalp actinic keratoses," British Journal of Dermatology, vol. 154, no. 1, pp. 146-149, 2006.

[74] R. H. Rosen, A. K. Gupta, and S. K. Tyring, "Dual mechanism of action of ingenol mebutate gel for topical treatment of actinic keratoses: rapid lesion necrosis followed by lesionspecific immune response," Journal of the American Academy of Dermatology, vol. 66, no. 3, pp. 486-493, 2012.

[75] J. M. Challacombe, A. Suhrbier, P. G. Parsons et al., "Neutrophils are a key component of the antitumor efficacy of topical chemotherapy with ingenol-3-angelate," Journal of Immunology, vol. 177, no. 11, pp. 8123-8132, 2006.

[76] F. R. Ali, C. Wlodek, and J. T. Lear, "The role of ingenol mebutate in the treatment of actinic keratoses," Dermatology \& Therapy, vol. 2, pp. 1-8, 2012.

[77] M. Lebwohl, N. Swanson, L. L. Anderson, A. Melgaard, Z. Xu, and B. Berman, "Ingenol mebutate gel for actinic keratosis," The New England Journal of Medicine, vol. 366, no. 11, pp. 1010-1019, 2012.

[78] S. Jäger, M. N. Laszczyk, and A. Scheffler, "A preliminary pharmacokinetic study of betulin, the main pentacyclic triterpene from extract of outer bark of birch (Betulae alba cortex)," Molecules, vol. 13, no. 12, pp. 3224-3235, 2008.

[79] C. Huyke, J. Reuter, M. Rödig et al., "Treatment of actinic keratoses with a novel betulin-based oleogel. A prospective, randomized, comparative pilot study," JDDG, vol. 7, no. 2, pp. 128-134, 2009.

[80] K. B. Corden, K. S. Gorski, S. J. Gibson et al., "Synthetic TLR agonists reveal functional differences between human TLR7 and TLR8," Journal of Immunology, vol. 174, no. 3, pp. 1259-1268, 2005.

[81] R. M. Szeimies, J. Bichel, J. P. Ortonne, E. Stockfleth, J. Lee, and T. C. Meng, "A phase II dose-ranging study of topical resiquimod to treat actinic keratosis," British Journal of Dermatology, vol. 159, no. 1, pp. 205-210, 2008.

[82] B. Berman and S. Amini, "Pharmacotherapy of actinic keratosis: an update," Expert Opinion on Pharmacotherapy, vol. 13, no. 13, pp. 1847-1871, 2012. 

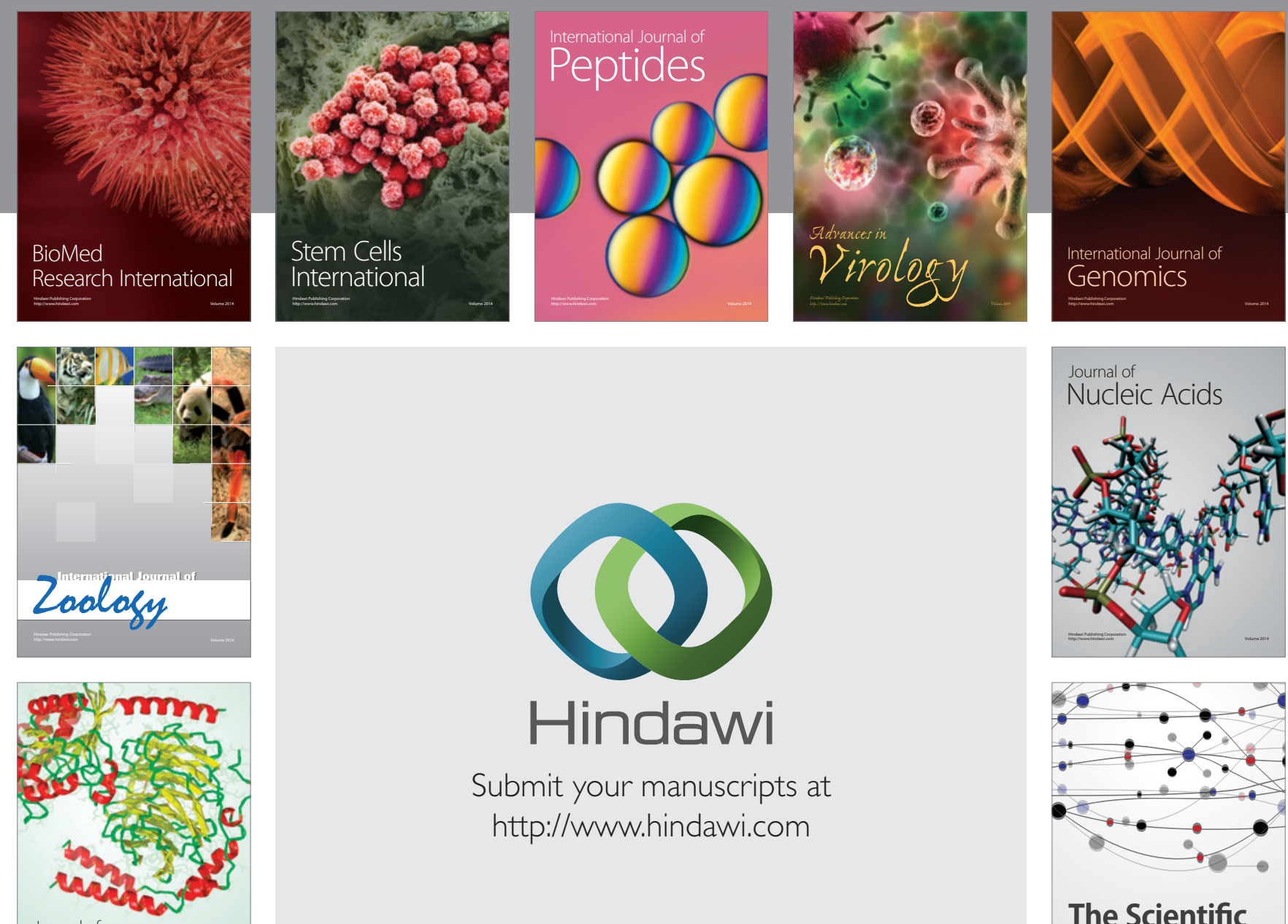

Submit your manuscripts at

http://www.hindawi.com

Journal of
Signal Transduction
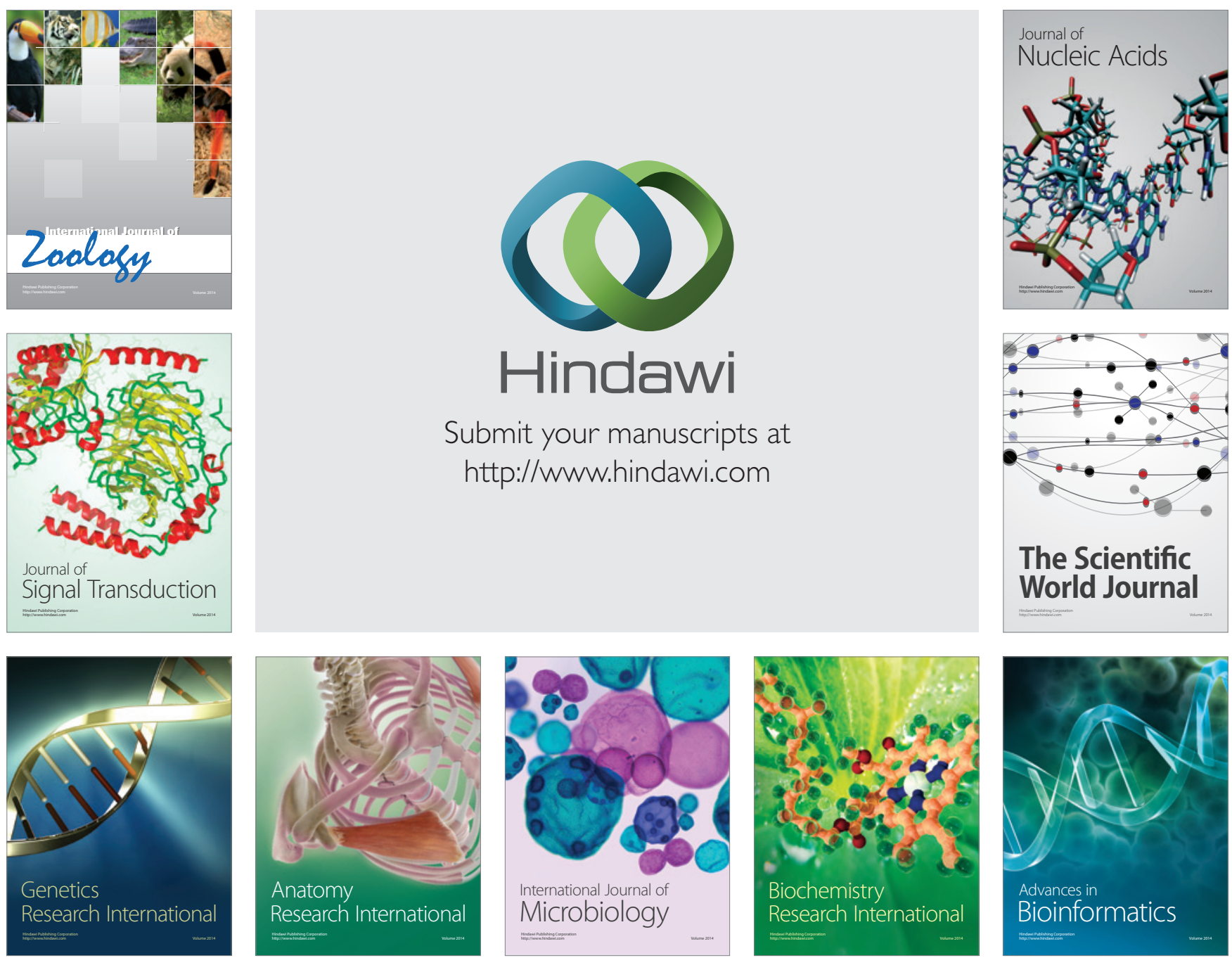

The Scientific World Journal
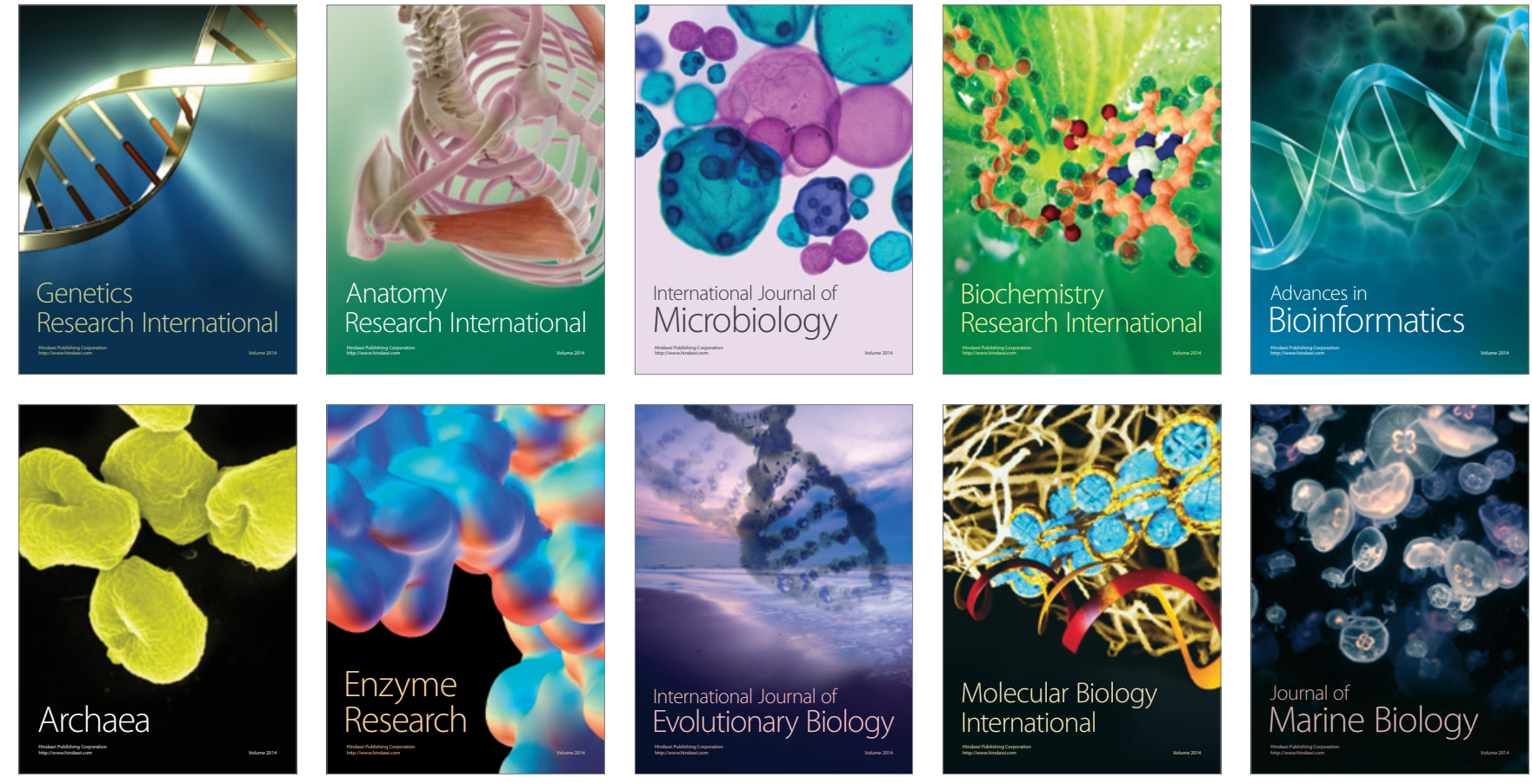